\title{
Risk of inter-river transmission of Gyrodactylus salaris by migrating Atlantic salmon smolts, estimated by Monte Carlo simulation
}

\author{
H. R. Høgåsen, E. Brun* \\ Section of Epidemiology, National Veterinary Institute, PO Box 8156, Dep, 0033 Oslo, Norway
}

\begin{abstract}
The possibility of Gyrodactylus salaris infection of wild North Atlantic salmon Salmo salar spreading to new rivers poses a major threat in Norway. This freshwater parasite can survive for some time in brackish water, and it has been suggested that smolts leaving infected rivers could transport vital parasites to new rivers. A Monte Carlo simulation model was used to estimate the risk that infected smolts would ascend a new river. Data from an infected watercourse in Norway, where the salmon population is maintained constant by cultivation, were used. The model included information on prevalence of infection, hydrographical conditions, survival of G. salaris in brackish water, fish population characteristics, and smolt behaviour during seaward migration. The annual risk was estimated for 3 neighbouring rivers situated at different distances from the index river. For the nearest river, which shares the same brackish water zone with the index river, the model estimated an annual risk of $31 \%$ that at least 1 infected smolt would ascend this river. The results of the simulation were highly sensitive to the water salinity along the migration route. For the other rivers, the annual risk was lower than $0.5 \%$. Risk was positively correlated with the number of fish leaving the index river, indicating control of this number as a possible tool in risk management.
\end{abstract}

KEY WORDS: Gyrodactylus salaris · Atlantic salmon · Inter-river transmission · Monte Carlo simulation

Resale or republication not permitted without written consent of the publisher

\section{INTRODUCTION}

Gyrodactylus salaris (Platyhelminthes: Monogenea) was introduced to Norway for the first time in 1973 to 1974. North Atlantic salmon are highly sensitive to infection and the parasite spreads rapidly, causing mass mortality in hatcheries and rivers (Bakke et al. 1990, Johnsen \& Jensen 1991). A model for infected rivers suggested a decrease in fry production from the second year post-infection. Within 5 yr most fry were infected and the production had declined to less than $5 \%$ of the pre-infection level (Johnsen \& Jensen 1986).

Salmon rivers in Norway had come under surveillance for Gyrodactylus salaris by the mid-1970s. In 1983, G. salaris infection became a notifiable disease, and the surveillance programme was extended to include fish farms. As Norwegian rivers are core areas for the reproduction of wild North Atlantic salmon, the overall aim has been to prevent further spread of $G$. salaris and the eradication of the parasite in as many rivers as possible (Johnsen \& Jensen 1991). By 2002, a total of 44 rivers were infected. Chemical treatment with rotenone has been used in 25 rivers, of which 15 have been successfully treated.

Gyrodactylus salaris was diagnosed in 1987 in fry from the Drammen watercourse, one of the 3 biggest watercourses in the SE part of Norway, which consists mainly of the rivers Drammenselva and Lierelva. Because of its vast estuary, rotenone treatment was not applicable. But instead of letting the disease run its course, which would have meant that the river would cease to be an attractive river for sport fishing, cultivation was continued in order to maintain the salmon population at pre-infection level. Parallel to this, intensified surveillance of all rivers in the region was initiated. 


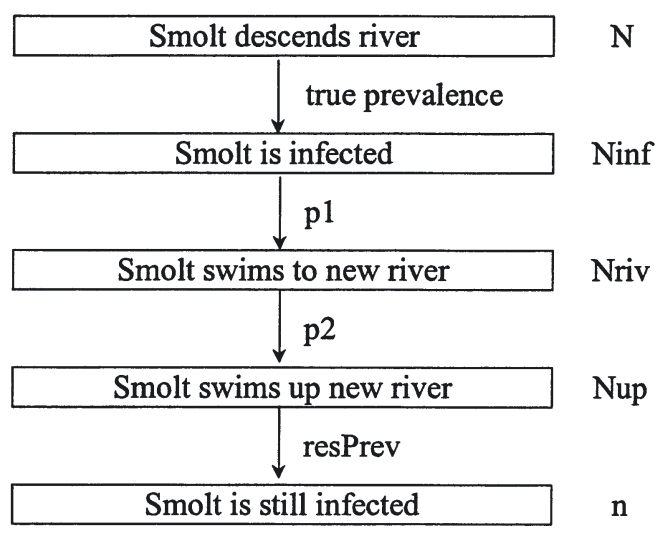

Fig. 1. Event tree used in model, showing probabilities that a given smolt will reach the subsequent step and resulting number of infected smolts migrating up new river (n). N: number of smolts decending river. p1, p2: probability of smolts migrating to new river and up new river, respectively

However, this policy has maintained an active infection in the river, allowing infected smolts to descend and migrate from the river each year. Gyrodactylus salaris is known to survive exposure to salinities encountered in estuaries (Soleng et al. 1998), and incompletely smoltified individuals may undertake migrations in the estuary and return to freshwater instead of migrating to the sea (Høgåsen 1998). It has been hypothesised that this migration has been the major cause for the inter-river spread of G. salaris within several fjord-river systems in Norway (Soleng et al. 1998). It is believed that $G$. salaris may have been transported through estuaries over distances of more than $35 \mathrm{~km}$ (Johnsen et al. 1999). When revising the national management plan for G. salaris in 2002, the Norwegian Animal Health Authority therefore asked for a quantification of the risk arising from the present cultivation practice to guide further decisions.

A quantification of this risk is hampered by major uncertainties about the behaviour of infected smolts as well as the salinities they encounter in the estuary. The Drammen watercourse has, however, been studied closely for many years, and data on the salmon population, the Gyrodactylus salaris-infection status and temperature and salinity profiles in the estuary are available, together with hydrographical profiles of the Oslofjord. Despite a paucity of behavioural data, a Monte Carlo simulation model was constucted from the available data on biological and physical systems, taking into account associated uncertainties and variabilities. The aim was to estimate the risk of 1 or more smolt(s) entering neighbouring rivers while still carrying viable $G$. salaris parasites from the Drammen watercourse.

\section{MATERIALS AND METHODS}

The model was based on the event tree illustrated in Fig. 1. The time frame was 1 yr. Probability distributions were used to account for uncertainty and variability of most variables in the model, which was run using the Microsoft Excel add-in program @Risk 4.5.2. professional edition (Palisade Corporation), with Latin Hypercube sampling and 50000 iterations. Sensitivity analysis was performed with Spearman's rank-correlation coefficients.

Number of smolts descending river (N). The yearly number of smolts descending the Drammen watercourse was estimated to 130000 based on release and capture data. Simulations were also run for 200000 , 65000 , and 13000 smolts to determine the effect of different options.

Number of infected smolts at Svelvik (Ninf). To reach other rivers, smolts have to swim through a narrow passage situated in the estuary, $10 \mathrm{~km}$ from the river mouth, by Svelvik (Fig. 2). The prevalence of Gyrodactylus salaris-infected smolts at this point was estimated from data of Soleng et al. (1998), who found G. salaris on 37 out of 52 smolts captured. According to these authors, test-sensitivity (Se) was close to 0.95 and specificity was 1 (T. Bakke pers. comm.). Testsensitivity was modelled using RiskPert $(0.9 ; 0.95 ; 1)$, test-specificity was set at 1 , true positives were calculated as 37/Se and true negatives as (52 - true positives). True prevalence was modelled by RiskBeta (true positives +1 ; true negatives +1 ) to account for variability and uncertainty (Vose 2000). The number of infected smolts was calculated as Ninf $=\mathrm{N} \times$ true prevalence.

Number of originally infected smolts migrating to new river (Nriv). No studies have been made of the behaviour of smolts infected with Gyrodactylus salaris in the estuary during seaward migration. Consensus of opinion estimates that between 1 of 1000 and 1 of 100000 infected smolts would swim to a new river annually. The probability that an infected smolt would swim to a new river (p1) was therefore modelled by RiskUniform $(0.00001 ; 0.001)$, and the number of infected smolts reaching the new river (Nriv) was modelled by RiskPoisson (Ninf $\times p 1)$. Poisson $(n p)$ was used as an approximation to the binomial distribution Binomial $(\mathrm{n} ; \mathrm{p})$ since $\mathrm{n}$ was large, $\mathrm{p}$ was small, and the Decker and Fitzgibbon criterion $\left(\mathrm{n}^{0.31} \mathrm{p}<0.47\right)$ remained true in all iterations (see Vose 2000 for further details).

Number of originally infected smolts migrating up new river (Nup). The consensus of opinion suggests that only a small fraction of smolts swimming to a new river would actually enter it immediately; most smolts would remain in the estuary long enough to allow the 


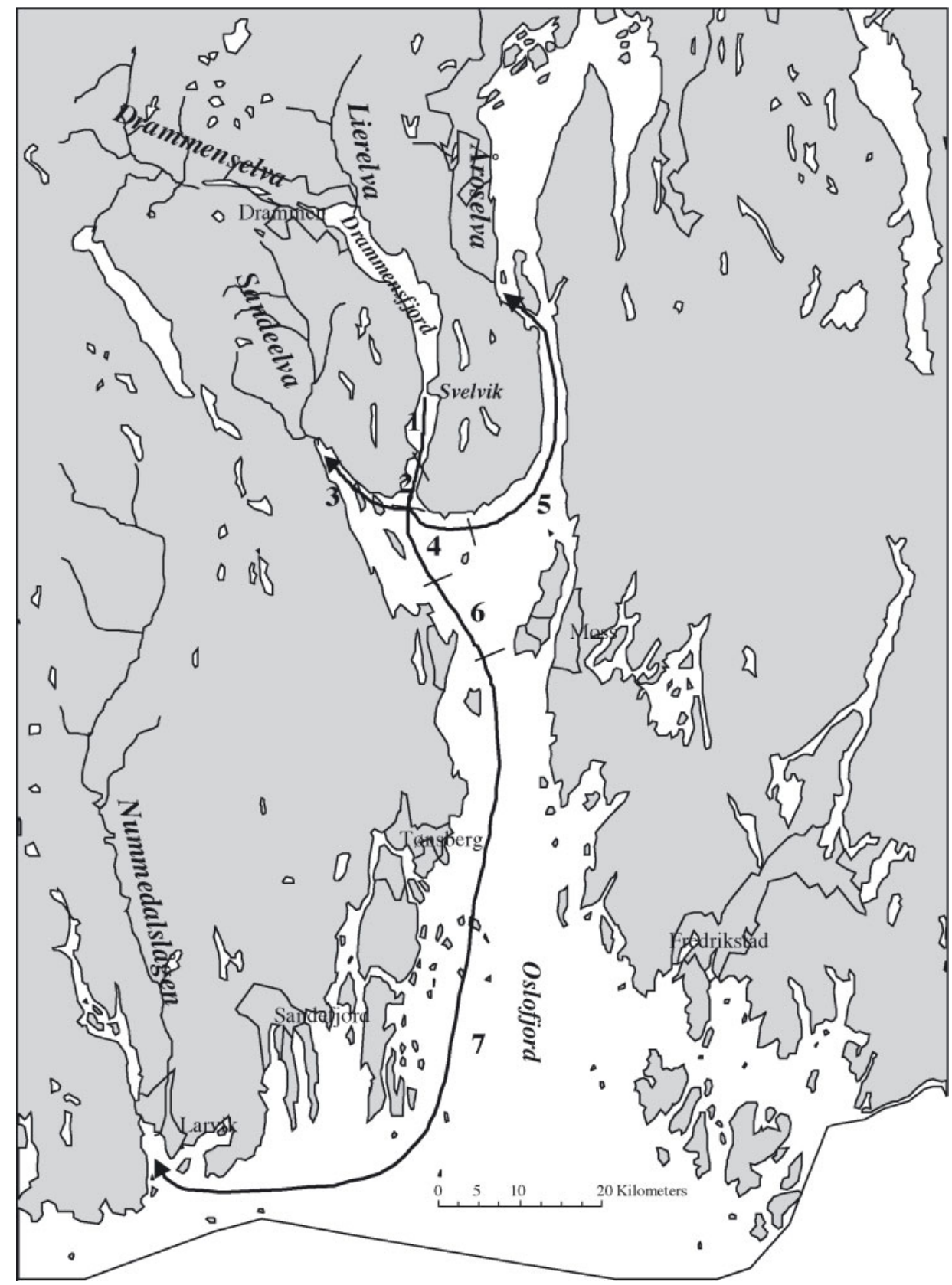

Fig. 2. Salmo salar. Migration routes of smolts from the Drammen watercourse to new rivers. 1 to 7 : different sectors of different salinity (see Table 1) along routes

saline water to clear them of Gyrodactylus salaris, or would continue to the sea. It has been suggested that between 1 of 10 and 1 of 100 infected smolts would actually swim immediately up the new river. The probability that an infected smolt would swim up the new river (p2) was therefore modelled by RiskUniform $(0.1 ; 0.01)$, and the number of fish entering the new river (Nup) was modelled by RiskBinomial (Nriv; p2).
Number of infected smolts migrating up new river (n). The smolts' migration through saline water would clear a number of them from Gyrodactylus salaris. We calculated the residual prevalence after migration (resPrev) by modelling the time spent in water of a given salinity and temperature, and applying these variables to survival data of G. salaris (Soleng \& Bakke 1997) (see following subsection). It was assumed that no fish would become infected during its migration in 
saline water. RiskBinomial (Nup; resPrev) was used to model the number of infected smolts swimming up a new river.

Residual prevalence of Gyrodactylus salaris after migration through saline water (resPrev). We used data on salinity and water temperature for periods corresponding to the flood conditions encountered by smolts during their migration to a new river (Pethon 1987). Based on data of M. Holm (pers. comm.) and the worst-case assumption that salinity is lowest in the main stream and at the surface, we assumed that smolts follow the main current and swim in the upper $3 \mathrm{~m}$ layer. The migration route was divided into different sectors according to the salinity data. Data from 22 different locations were used and 7 sectors were defined (Fig. 2). Variations in salinity in Sectors 1 to 6 were based on individual data and modelled by an empirical cumulative distribution, as described by Vose (2000) (Table 1). For Sector 7, salinity data were only given as means (SD) for 5 different years, and normal distributions were assumed. The time spent in each sector was calculated by dividing distance by swimming speed. Swimming speed (Table 1) was modelled for each sector as a distribution based on release-capture data in the area (Pethon \& Hansen 1990). Finally, residual prevalence was calculated on the basis of experimental data published by Soleng \& Bakke (1997), who used salmon parr and G. salaris originating from Lierelva (Fig. 2). Their results were extrapolated to a water temperature of $10^{\circ} \mathrm{C}$ (based on assumed linearity between 6 and $12^{\circ} \mathrm{C}$ ) and to differ- ent salinities $(5,6 \%$, etc.) (based on assumed linearity between the salinities tested: 0, 5, 7.5, 10, 15, 20 and $33 \%$ ). We chose $10^{\circ} \mathrm{C}$ on the basis of temperatures recorded during the period of downstream migration (Soleng et al. 1998, D. Danielssen pers. comm.). According to Soleng et al. (1998), the temperature in the 0 to $8 \mathrm{~m}$ layer depth was relatively stable during the migration period $\left(10.0\right.$ to $10.5^{\circ} \mathrm{C}$ at the surface, 9.0 to $11.5^{\circ} \mathrm{C}$ at $8 \mathrm{~m}$ depth).

Summary statistics of the data generated during the simulation for the input variables are shown in Table 1.

\section{RESULTS}

\section{Number of infected smolts migrating up new river (n)}

The most likely result for all 3 rivers was that no infected smolts would migrate up a new river with viable parasites in a given year, even when 200000 smolts left the Drammen watercourse. For the 2 rivers situated at the greatest distance from the Drammen watercourse, the probability of such an event was higher than $99.5 \%$ for all scenarios tested. For the nearest river, Sandeelva, the probability that no infected smolts would ascend was $69 \%$ for the basic case (130000 smolts), $66 \%$ if 200000 smolts were to leave the Drammen watercourse yearly, and $92 \%$ if this decreased to 13000 . The probability mass function of the estimated number of smolts migrating up

Table 1. Distributions used for input data to model. For each variable, @Risk formula is given, with minimum, maximum and mean of the 50000 values generated during the simulation. Prevalence: prevalence of Gyrodactylus salaris among downstream migrating smolts Salmo salar; p1: probability of smolts migrating to new river; p2: probability of smolts migrating up new river; Speed: swimming speed of migrating smolts in the different sectors. Probabilities range from 0 to 1 , salinities are given in \%o and swimming speeds are given in $\mathrm{km} 24 \mathrm{~h}^{-1}$

\begin{tabular}{|c|c|c|c|c|}
\hline Variables & Distribution (@Risk function) & Min. & Max. & Mean \\
\hline Test-sensitivity (Se) & RiskPert $(0.9 ; 0.95 ; 1)$ & 0.901 & 0.999 & 0.95 \\
\hline Prevalence & $\operatorname{RiskBeta}\left(\alpha_{1} ; \alpha_{2}\right)$ & 0.46 & 0.95 & 0.74 \\
\hline p1 & RiskUniform $(0.00001 ; 0.001)$ & 0.00001 & 0.001 & 0.0005 \\
\hline $\mathrm{p} 2$ & RiskUniform $(0.01 ; 0.1)$ & 0.01 & 0.1 & 0.055 \\
\hline \multicolumn{5}{|l|}{ Salinity } \\
\hline Sector 1 & RiskCumul $(1 ; 15 ;\{x i\} ;\{$ pi $\})$ & 1.0 & 15.0 & 5.0 \\
\hline Sector 2 & $\operatorname{RiskCumul}(4 ; 14 ;\{\mathrm{xi}\} ;\{\mathrm{pi}\})$ & 4.0 & 14.0 & 7.9 \\
\hline Sector 3 & $\operatorname{RiskCumul}(4 ; 16 ;\{\mathrm{xi}\} ;\{\mathrm{pi}\})$ & 4.0 & 16.0 & 10.5 \\
\hline Sector 4 & $\operatorname{RiskCumul}(11 ; 24 ;\{x i\} ;\{$ pi $\})$ & 11.0 & 24.0 & 14.8 \\
\hline Sector 5 & $\operatorname{RiskCumul}(13 ; 29 ;\{x i\} ;\{p i\})$ & 13.0 & 29.0 & 18.9 \\
\hline Sector 6 & $\operatorname{RiskCumul}(13 ; 29 ;\{x i\} ;\{p i\})$ & 13.0 & 29.0 & 17.7 \\
\hline Sector 7 & RiskNormal(20.6;5.3) & 0.16 & 41.9 & 20.6 \\
\hline \multicolumn{5}{|l|}{ Speed } \\
\hline Sectors 1, 2 & RiskTrigen $(0.03 ; 0.15 ; 0.44 ; 10 ; 90 ;$ RiskTruncate $(0 ;))$ & 0.0003 & 15.0 & 5.8 \\
\hline Sectors 3,4 & RiskTrigen $(0.02 ; 0.04 ; 0.06 ; 10 ; 90 ;$ RiskTruncate $(0 ;))$ & 0.1 & 1.8 & 1.0 \\
\hline Sectors $5,6,7$ & RiskTrigen $(0.44 ; 0.7 ; 0.85 ; 10 ; 90 ;$ RiskTruncate $(0 ;))$ & 6.3 & 23.9 & 15.7 \\
\hline
\end{tabular}




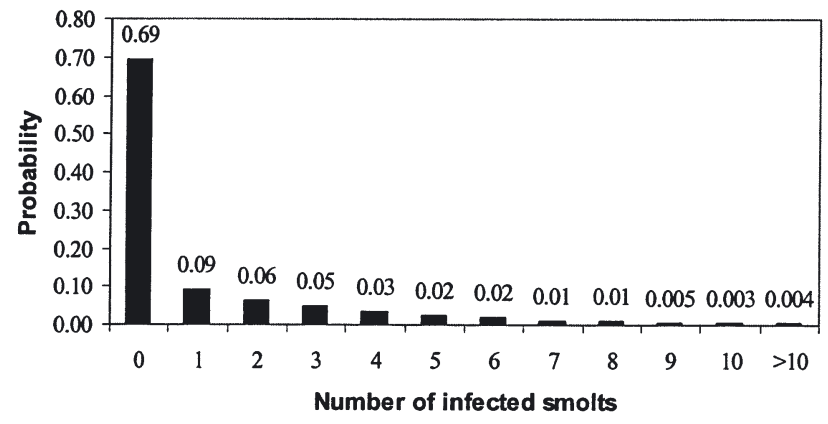

Fig. 3. Salmo salar. Estimated number of smolts with viable Gyrodactylus salaris migrating up Sandeelva each year, assuming that 130000 smolts migrate from the Drammen water course

Sandeelva infected with viable Gyrodactylus salaris, given that 130000 smolts migrate down the Drammen watercourse, is shown in Fig. 3. The 95\% confidence interval was 0 to 7 infected smolts, and the maximum was 17. Results for other scenarios and rivers are shown in Table 2.

\section{Residual prevalence of Gyrodactylus salaris after migration to new river (resPrev)}

The model estimated that the prevalence of infection was always below $34 \%$ and $21 \%$ of the original prevalence in smolts migrating to Åroselva and Numedalslågen, respectively. The probability that all smolts migrating to these rivers were cleared of infection was 90 and $98 \%$, respectively. In contrast, the model predicted no reduction in prevalence in smolts migrating to Sandeelva in $26 \%$ of the iterations. The probability that the migration cleared infection from all smolts

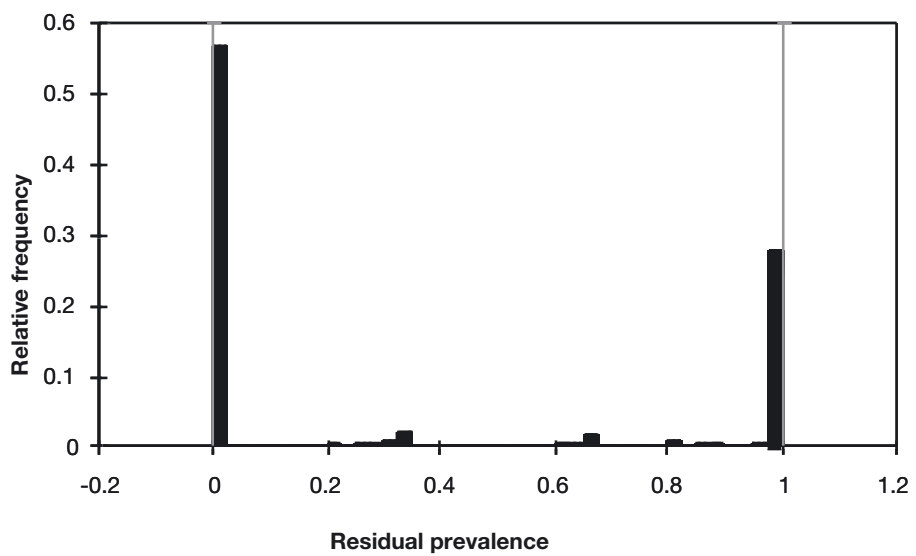

Fig. 4. Salmo salar infected with Gyrodactylus salaris. Residual prevalence of infection in initially infected smolt after migration to Sandeelva
Table 2. Salmo salar. Estimated number of infected Gyrodactylus salaris-smolts migrating up new rivers. Results are shown in relation to number emigrating from Drammen watercourse per year $(\mathrm{N})$. For each scenario, estimated number of smolts migrating up new river are shown as mean value, $95 \%$ confidence interval (CI) (2.5 to $97.5 \%$ ), maximum value, and the probability that no smolts infected with G. salaris would migrate up the river, (p [0])

\begin{tabular}{|c|c|c|c|c|c|}
\hline Rivers & $\mathrm{N}$ & Mean & $95 \% \mathrm{CI}$ & Max & $\mathrm{p}(0) \%$ \\
\hline \multicolumn{6}{|c|}{ Sandeelva } \\
\hline & 13000 & 0.1 & $0-1$ & 5 & 91.9 \\
\hline & 65000 & 0.5 & $0-4$ & 11 & 76.5 \\
\hline & 130000 & 1.0 & $0-7$ & 17 & 69.2 \\
\hline & 200000 & 1.5 & $0-10$ & 25 & 65.7 \\
\hline \multicolumn{6}{|c|}{ Åroselva } \\
\hline & 13000 & 0.0004 & $0-0$ & 1 & 99.96 \\
\hline & 65000 & 0.002 & $0-0$ & 3 & 99.83 \\
\hline & 130000 & 0.003 & $0-0$ & 5 & 99.70 \\
\hline & 200000 & 0.006 & $0-0$ & 5 & 99.55 \\
\hline \multicolumn{6}{|c|}{ Numedalslågen } \\
\hline & 13000 & 0 & $0-0$ & 0 & 100.00 \\
\hline & 65000 & 0.0002 & $0-0$ & 2 & 99.98 \\
\hline & 130000 & 0.0003 & $0-0$ & 2 & 99.97 \\
\hline & 200000 & 0.0004 & $0-0$ & 4 & 99.97 \\
\hline
\end{tabular}

migrating to Sandeelva was $56 \%$. The relative frequency of the residual prevalences after migration to Sandeelva is shown as a relative frequency plot in Fig. 4.

\section{Sensitivity analysis}

The number of infected smolts ascending Sandeelva (output variable) was most strongly correlated with salinity in the Sandeelva estuary (Sector 3), with a correlation coefficient of -0.65 (Spearman's rank correlation). The proportions of smolts migrating to this river (p1) and up this river (p2) displayed correlation coefficients with the output of 0.23 and 0.17 , respectively, whereas other inputs had correlation coefficients lower than 0.1. The number of infected smolts ascending Åroselva and Numedalslågen was weakly correlated with all input distributions (correlation coefficients $<0.1)$.

\section{DISCUSSION}

The results suggest that there may be a significant risk that downstream migrating smolts could transport Gyrodactylus salaris to other rivers. The annual risk that at least 1 Atlantic salmon smolt infected with $G$. salaris would enter Sandeelva, which is situated $30 \mathrm{~km}$ from the outlet of the Drammen watercourse, was esti- 
mated at $31 \%$. However, for Åroselva and Numedalslågen, situated 47 and $103 \mathrm{~km}$ from the outlet of the watercourse, respectively, the annual risks were considerably lower $(0.3$ and $0.03 \%$, respectively).

The higher risk for Sandeelva is related to the fact that it is situated closer to and drains into the same basin as the Drammen watercourse (Fig. 2). The upper layers of this basin consist of brackish water during spring flooding. The survival of Gyrodactylus salaris is negatively correlated with salinity in the range 7.5 to $33.0 \%$, and its numbers may increase at salinities up to $5 \%$ (Soleng \& Bakke 1997). The model suggested that smolts were frequently exposed to salinities too low to efficiently eliminate all parasites. No specific salinity data, however, is available for the Sandeelva estuary, and values for this stage of the migration were derived from data for stations at the outlet of the Drammen watercourse estuary. Sensitivity analysis showed that salinity was the most influential variable for the final risk estimates; this is consistent with results of Paisley et al. (1999) concerning the risk of transmission of G. salaris from farmed salmon to the Tana River, Norway. This emphasises the need for sufficient data on this variable to enable quantification of the risk. Sandeelva is much smaller than the Drammen watercourse, and will probably have less impact on the adjacent estuary during spring flooding. The salinity estimates we used may therefore be lower than the true values, leading to an overestimation of the survival of parasites and thus of the risk of viable parasites being introduced to this river.

The main uncertainties in the model (and possibly also the main variable factors) are related to the behaviour of infected salmon smolts in the estuary. Little is known about migrating smolts after they leave their home river, and even less about Gyrodactylus salarisinfected smolts. Short migrations of incompletely smoltified individuals to the estuary are mainly observed in stocks that require many years to achieve full smoltification, such as stocks in cold latitudes (Høgåsen 1998). Salmon smolts from the Drammen watercourse usually leave the home river at an age of 2 yr (Hansen et al. 1996), suggesting that such short migrations are absent or rare in this stock. However, Soleng et al. (1998) emphasized the need to examine the possibility of abnormal behaviour in infected smolts. Factors regulating smoltification, onset of migration, and adaptation to seawater are complex processes (Høgåsen 1998), and each could theoretically be affected by infection. G. salaris could cause severe osmotic problems and secondary infections in fry, and lesions on skin and gills represent an additional challenge during smoltification and seaward migration. Infected smolts caught in the estuary close to Svelvik had a parasite intensity ranging from 0 to 1105 individuals per smolt, with an average of 51.8
(Soleng et al. 1998). Less infected smolts might swim directly to the sea, which would account for the satisfactory number of returning adults (typically 6 to $7 \%$ of released parr or smolts; Hansen et al. 1996), while the most heavily infected smolts would take longer to adapt to a higher salinity, and might even choose to remain in the estuary or return to freshwater instead of migrating to the sea. Since they would not be sexually maturing, they would have less motivation to return to their home river, increasing the chance that they would enter another nearby river (Høgåsen 1998). On the other hand, osmotic stress and isolation from the school of migrating smolts might increase their risk of mortality through predation, which is very intense in the Drammensfjord (L. Hansen pers. comm.). Therefore, the probability that a smolt would migrate directly to a new river and undertake an upstream migration was estimated to be small; the range was wide to account for lack of data and the great uncertainty. The sensitivity analysis indicated that these parameters had some effect on the estimates for Sandeelva, that this effect was less than that of salinity in fluctuations in the Sandeelva estuary. More data on the destination of seaward-migrating smolts infected with G. salaris would strengthen the validity of the results.

The model assumes that infected smolts migrate over the shortest distance from the Drammen watercourse to the new rivers, thus keeping the time spent in brackish water to a minimum. However time and distance may be irrelevant when salinity is so low that it does not affect Gyrodactylus salaris, and conversely important when salinity is high enough to affect survival of the parasite (Soleng et al. 1998). Migration patterns of salmonids are affected by smolt physiology, tidal currents, movement of surface water and local coastal currents (LaBar et al. 1978, McCleave 1978, Tytler et al. 1979, Høgåsen 1998). In the Oslofjord, the movement of the upper water layer is mainly controlled by tidal currents and wind (Gade 1970). Few of our data were related to current, and inclusion of this variable would have seriously complicated the model without necessarily improving the reliability of the estimates. The swimming speeds used in the model were estimated from capture-release data in some of the sectors considered in the simulation and corresponded well with other estimates of migration speed in smolts (Økland et al. 2002). Using shortest distance as input data underlines a worst-scenario approach. The sensitivity analysis suggested that the results were negligibly affected by swimming speed in the ranges used.

The model assumes that, within a sector, a given smolt would be exposed to the same salinity level. The bimodal pattern of residual prevalence for Sandeelva (Fig. 4) illustrates that, in most iterations, the smolt 
would either cross no barriers of high-salinity water, leaving parasite prevalence unaffected, or cross at least 1 such barrier, reducing prevalence to zero. In fact, combinations of tide, wind and air pressure may locally cause rapid changes in salinity and temperature (Pethon 1987), and migrating smolts may be exposed to varying conditions during their migration. We also know that migrating smolts frequently make short dives to depths at which salinity is higher than in the surface layers (M. Holm pers. comm.). However, we have no data on how such rapid changes affect parasite survival, and the present model simplification was therefore used. The normal variability associated with rain and flood on a daily basis was nevertheless accounted for by using probability distributions to model water salinity.

A certain validation of the model was possible, since an intense surveillance programme of all neighbouring rivers has been running since the parasite was detected in 1987. No infected fish have so far been found in any of the other rivers studied during this period (1988 to 2002). If we assume that the yearly risk of infection has been constant, this historical information makes us $99 \%$ confident that the yearly risk of infection of Sandeelva is less than $26 \%$, which is lower than the estimated yearly risk of at least 1 infected smolt entering the river ( $31 \%)$. However, this empirical information is a measure of the establishment of infection, while the model estimates only whether infected smolts swim up the river, not whether this leads to river infection. The model is consistent with surveillance data if the introduction of more than 1 infected smolt is necessary to infect the river. Infection of a new river depends on a number of factors such as parasite intensity on the upstream migrants and the probability that infectious smolts swim sufficiently far up the river to allow effective transmission. Even should prevalence not be reduced after migration to the river, the intensity of parasites and their ability to reproduce and undergo transmission to other fish might be. This ability might moreover decrease after the fish have enter freshwater. Soleng et al. (1998) exposed 12 infected parr from local stock to brackish water $(20.0 \%)$ for $8 \mathrm{~h}$ and then returned them to freshwater. Of these, 10 were still infected immediately after exposure, but after $7 \mathrm{~d}$ in freshwater only 3 were infected, and after $14 \mathrm{~d}$, only 2. Expanding our model to include these variables would probably show that the risk of establishing infection is less than the present estimate. In addition, upstream migration of infected smolts is only one among several possibilities of infection of the river. There is a constant release of parasites into the estuary from the infected rivers and infected fish, and freefloating parasites might attach to a number of species in brackish water such as migrating adult salmonids (including escapes of farmed salmon), flounder Platichtys flesus, 3-spined stickleback Gasterosteus aculeatus and 9-spined stickleback Pungitius pungitius, all of which could transport the parasites into a new river (Soleng et al. 1998, Soleng \& Bakke 1998).

A model cannot provide a full answer to a problem, but may provide information required for future decisions and may reveal important data gaps. It is therefore essential that a model itself, its assumptions, the shortcomings of its data, and the consequences implied are transparent to risk managers. It is important that the framework of a model be dynamic and capable of absorbing new information. The present model allows such improvements, and can easily be adapted to other species and geographical areas for which similar data are available. For the system examined herein, the model indicates that the risk of at least 1 downstream-migrating smolt infected with Gyrodactylus salaris entering a new river is significant for Sandeelva and very low for Åroselva and Numedalslågen. The magnitude of the risk is related to the number of smolts leaving the index river and illustrates how manipulating or controlling this number is a possible tool in risk management. Empirical observation together with our results indicated that several infected smolts are necessary to establish infection, or that the model overestimates the risk of infected smolts swimming up Sandeelva. There is a need to gather more information about the behaviour of infected smolts as well as local salinity data in the estuary of Sandeelva in order to improve our estimates.

Acknowledgements. We wish to thank D. Danielssen, M. Holm, T. A. Bakke, E. Garnås, L. P. Hansen, E. Mathiesen, T. A. Mo, L. G. Paisley, J. Hostrup-Pedersen, P. Pethon, and M. Sandberg for providing data or constructively criticising the model and our assumptions. We're also grateful to B. T. Heier for drawing the chart of the rivers and connecting fjord systems.

\section{LITERATURE CITED}

Bakke TA, Jansen PA, Hansen LP (1990) Differences in the host resistance of Atlantic salmon, Salmo salar L., stocks to the monogenean Gyrodactylus salaris Malmberg, 1957. J Fish Biol 37:577-587

Gade HG (1970) Hydrographic investigation in the Oslofjord, a study of water circulation and exchange processes, Vols 1-3. Geophysic Institute, University of Bergen

Hansen LP, Jonsson B, Jonsson N (1996) Overvåking av laks fra Imsa og Drammenselva. NINA Oppdragsmeld. 401: $1-28$

Høgåsen HR (1998) Physiological changes associated with the diadromous migration of salmonids. Can Spec Publ Fish Aquat127:

Johnsen BO, Jensen AJ (1986) Infestations of Atlantic salmon, Salmo salar, by Gyrodactylus salaris in Norwegian rivers. J Fish Biol 29:233-241 
Johnsen BO, Jensen AJ (1991) The Gyrodactylus story in Norway. Aquaculture 98:289-302

Johnsen BO, Hvidsten NA, Møkkelgjerd PI (1999) Lakseelver i Trondheimsfjorden. NINA Oppdragsmeld 598:1-38

LaBar GW, McCleave JD, Fried SM (1978) Seawater migration of hatchery-reared Atlantic salmon (Salmo salar) smolts in the Penobscot river estuary, Maine: open water movements. J Cons Perm Int Explor Mer 38:257-269

McCleave JD (1978) Rhythmic aspects of estuarine migration of hatchery-reared Atlantic salmon (Salmo salar) smolts. J Fish Biol 12:559-570

Økland F, Thorstad E, Finstad B, Scott McKinley R (2002) Estimating sea lice infestation on Atlantic salmon and sea trout smolts in a Norwegian fjord. Poster presented at AquaNet II, Second Research Conference and Annual Meeting of AquaNet i New Brunswick, Canada, 14-17 September. Available at: www.nina.no/archive/nina/Info/ Konferanser/PosterAqua.pdf pr. 26/6/03

Paisley LG, Karlsen E, Jarp J, Mo TA (1999) A Monte Carlo simulation model for assessing the risk of introduction of Gyrodactylus salaris to the Tana river, Norway. Dis Aquat Org 37:145-152

Pethon P (1987) Salinitetsmålinger i Drammensfjorden og Oslofjorden høsten 1987. Teknisk notat nr. 1. Direktoratet for Naturforvaltning, Trondheim

Editorial responsibility: Wolfgang Körting,

Hannover, Germany
Pethon P, Hansen LP (1990) Migration pattern of Atlantic salmon smolts Salmo salar L. released at different sites in the River Drammenselv, SE Norway. Fauna Norv Ser A 11: 17-22

Soleng A, Bakke TA (1997) Salinity tolerance of Gyrodactylus salaris (Platyhelminthes, Monogenea): laboratory studies. Can J Fish Aquat Sci 54:1837-1845

Soleng A, Bakke TA (1998) The susceptibility of three-spined stickleback (Gasterosteus aculeatus), nine-spined stickleback (Pungitius pungitius) and flounder (Platichthys flesus) to experimental infections with the monogenean Gyrodactylus salaris. Folia Parasitol (Ceske Budejovice) 45:270-274

Soleng A, Bakke TA, Hansen LP (1998) Potential for dispersal of Gyrodactylus salaris (Platyhelminthes, Monogenea) by sea-running stages of the Atlantic salmon (Salmo salar): field and laboratory studies. Can J Fish Aquat Sci 55: 507-514

Tytler P, Thorpe JE, Shearer WM (1979) Ultrasonic tracking of the movements of the Atlantic salmon smolts (Salmo salar L.) in the estuary of two Scottish rivers. J Fish Biol 12: 575-586

Vose D (2000) Risk analysis: a quantitative guide. John Wiley \& Sons, Chichester

Submitted: July 10, 2003; Accepted: September 25, 2003

Proofs received from author(s): December 17, 2003 